\title{
Serum ferritin and primary lung cancer
} \\ ${ }^{1}$ Department of Clinical Laboratory, Guangxi Medical University Affiliated Tumor Hospital, Nanning 530021, Guangxi Province, \\ P.R. China \\ ${ }^{2}$ Experimental Research Department, Guangxi Medical University Affiliated Tumor Hospital, Nanning 530021, Guangxi \\ Province, P.R. China \\ ${ }^{3}$ Department of Hepatobiliary Surgery, Guangxi Medical University Affiliated Tumor Hospital, Nanning 530021, Guangxi \\ Province, P.R. China \\ Correspondence to: Bo Zhu, email: profbozhu@163.com
}

Keywords: primary lung cancer, Serum ferritin, Hemoglobin, Transferrin, Menopause

Abbreviations: serum ferritin (SF); tumor-nodes-metastasis (TNM); hemoglobin (Hb); transferrin (TRF)

Received: July 28, $2017 \quad$ Accepted: September 04, $2017 \quad$ Published: October 04, 2017

Copyright: Chen et al. This is an open-access article distributed under the terms of the Creative Commons Attribution License 3.0 (CC BY 3.0), which permits unrestricted use, distribution, and reproduction in any medium, provided the original author and source are credited.

\section{ABSTRACT}

\begin{abstract}
Existing research yields conflicting results regarding the relation between iron deficiency and high serum ferritin (SF) levels in primary lung cancer patients. We investigated the concentrations of SF, hemoglobin (Hb) and transferrin (TRF) in 569 male primary lung cancer patients and 252 female primary lung cancer patients. We grouped the subjects according to gender, smoking status, menopausal status, pathological type, stage, and TNM stage. The levels of SF and TRF were correlated with T stage in male patients $(p<0.01)$. The levels of SF and TRF were correlated with menopausal status in female patients $(p<0.01)$. Hb was correlated with smoking status, pathological type, stage, and TNM stages in male patients $(p<0.01)$, but in female patients, Hb was not correlated with these grouping factors $(p>0.05)$. The levels of SF may be regulated by different mechanisms and may be of different physiological significance in different populations.
\end{abstract}

\section{INTRODUCTION}

Recent work has shown that iron has a role in the tumor microenvironment and in metastasis [1]. Cancer cells exhibit an enhanced dependence on iron relative to their normal counterparts, a phenomenon called iron addiction $[2,3]$. A higher intake of heme iron has shown a tendency toward a positive relation with cancer risk [4]. The World Health Organization recommended that serum ferritin (SF) concentrations was the best indicator of iron deficiency [5]. So SF has aroused our concern. SF is highly expressed in tumor tissues and serum of patients with non-small cell lung cancer [6]. High expression of SF in non-small cell lung cancer may be also the result of inflammation and oxidative stress [6]. Infection or inflammation generate anemia and profound changes in iron metabolism, and SF increases with infections $[7,8]$. Microbes have an essential need for iron, which is required for many microbial metabolic processes and for microbial pathogenicity [9]. SF levels could be used to differentiate between fever of unknown origin caused by infectious and noninfectious diseases $[10,11]$. These changes are important confounders to consider in assessments of SF status.

However, studies have shown that iron deficiency in lung cancer patients is as high as $50.7 \%$ [12]. One study found that the high SF levels are not equal to high iron content of SF. In this study, the iron content of SF was below the normal reference values in $90 \%$ Hemodialysis patients [13], which is also found in non-small cell lung cancer patients [6]. There might be the presence of oligoelements other than iron inside the SF core [13]. A dietary survey of a region with a high incidence of lung cancer in Southwest China found that cadmium and titanium were significantly higher in the lung cancer group than in the control group [14]. Based on these studies, we speculated that SF containing oligoelements stimulated tissues to produce tumors. Tumor tissue also stimulated 
Table 1: Patients' characteristics

\begin{tabular}{|c|c|c|c|c|}
\hline \multirow{2}{*}{ Parameters } & \multicolumn{2}{|c|}{ Men } & \multicolumn{2}{|c|}{ Women } \\
\hline & $\mathbf{N}$ & $\%$ & $\mathbf{N}$ & $\%$ \\
\hline Number of patients & 569 & & 252 & \\
\hline \multicolumn{5}{|l|}{ Smoking status } \\
\hline Smoker & 414 & 72.8 & 0 & 0.0 \\
\hline Never & 155 & 27.2 & 252 & 100.0 \\
\hline \multicolumn{5}{|l|}{ Menopause } \\
\hline Yes & & & 180 & 71.4 \\
\hline No & & & 72 & 28.6 \\
\hline \multicolumn{5}{|l|}{ Pathologic type } \\
\hline Adenocarcinoma & 301 & 52.9 & 197 & 78.2 \\
\hline Squamous cell carcinoma & 171 & 30.1 & 25 & 9.9 \\
\hline Adeno-squamous carcinoma & 18 & 3.2 & 8 & 3.2 \\
\hline Small cell carcinoma & 53 & 9.3 & 8 & 3.2 \\
\hline Not classifiable/Others & 26 & 4.6 & 14 & 5.6 \\
\hline \multicolumn{5}{|l|}{ Stage } \\
\hline I & 96 & 16.9 & 64 & 25.4 \\
\hline II & 46 & 8.1 & 17 & 6.7 \\
\hline III & 194 & 34.1 & 60 & 23.8 \\
\hline IV & 182 & 32.0 & 97 & 38.5 \\
\hline Not classifiable & 51 & 9.0 & 14 & 5.6 \\
\hline \multicolumn{5}{|l|}{ TNM } \\
\hline $\mathrm{T} 1$ & 76 & 13.4 & 62 & 24.6 \\
\hline $\mathrm{T} 2$ & 223 & 39.2 & 106 & 42.1 \\
\hline $\mathrm{T} 3$ & 123 & 21.6 & 37 & 14.7 \\
\hline $\mathrm{T} 4$ & 87 & 15.3 & 25 & 9.9 \\
\hline Tx (Not classifiable) & 60 & 10.5 & 22 & 8.7 \\
\hline N0 & 131 & 23.0 & 76 & 30.2 \\
\hline N1 & 54 & 9.5 & 21 & 8.3 \\
\hline $\mathrm{N} 2$ & 203 & 35.7 & 88 & 34.9 \\
\hline $\mathrm{N} 3$ & 121 & 21.3 & 45 & 17.9 \\
\hline Nx (Not classifiable) & 60 & 10.5 & 22 & 8.7 \\
\hline M0 & 337 & 59.2 & 141 & 56.0 \\
\hline M1 & 181 & 31.8 & 97 & 38.5 \\
\hline Mx (Not classifiable) & 51 & 9.0 & 14 & 5.6 \\
\hline
\end{tabular}


the body to produce more SF, and SF stored oligoelements for tumor cell consumption.

Existing research yields conflicting results regarding the relation between iron deficiency and high SF levels in primary lung cancer patients. The contradiction between iron deficiency and high SF levels in primary lung cancer patients is more prominent in advanced diseases, deterioration, and solid tumors, such as lung tumors $[6,12]$. There is not much clinical research on the relation between SF and primary lung cancer. We will investigate the relation between SF and pathological types, tumor-nodes-metastasis (TNM) stage, smoking status, menopausal status. Besides, hemoglobin $(\mathrm{Hb})$ and transferrin (TRF). We are going to discuss by gender, since the SF levels and $\mathrm{Hb}$ levels in women are different from in men.

\section{RESULTS}

\section{Patients' characteristics}

A total of 830 patients were initially diagnosed as primary lung cancer. 3 female smokers and 6 male former smokers were excluded due to they were uncommon cases. 821 patients with primary lung cancer were included in the study. Table 1 summarizes patients' characteristics of age, smoking status, menopausal status, pathological type, stage, TNM stage. At the time of diagnosis, the male patients ranged from 28 to 86 years of age with an average age of 58.9 years, and female patients aged from 25 to 80 years of age with an average age of 54.7 years. In male patients, the proportion of smokers was greater than non-smokers. Adenocarcinoma was the most common pathological type of lung cancer in both male patients and female patients. The proportion of advanced lung cancer was higher than that of early lung cancer at initial diagnosis.

\section{The characteristics of $\mathrm{SF}, \mathrm{Hb}, \mathrm{TRF}$ in male primary lung cancer patients}

The characteristics among SF, Hb, TRF and smoking status, pathological types, stage, TNM stage in male primary lung cancer patients are shown in Table 2. After chi-square test, there was no difference in the constituent ratio of smoking patients and non-smoking patients in different groups $(p>0.05)$ (Supplementary Table 2). Smoking bias had been excluded in groups of pathological type, stage and TNM stage.

$\mathrm{Hb}$ levels were significantly different in smoking status, pathologic types, stage, $\mathrm{T}$ stage and $\mathrm{N}$ stage ( $p$ $<0.01)$. The prevalence of anemia among smokers was twice that of non-smokers. Squamous cell carcinoma and adeno-squamous carcinoma were two pathologic types with high prevalence of anemia in male primary lung cancer patients. The higher the stage, the higher the prevalence of anemia. But the prevalence of anemia in stage III was higher than in stage IV. This phenomenon was the same in T3 stage and N3 stage, and this should be noted. Metastasis had no effect on anemia $(p>0.05)$. The mean SF levels in all groups exceeded the normal range (15 ug/l-200 ug/l). SF levels and TRF levels were significantly different in T stage $(p<0.01)$.

\section{The characteristics of $\mathrm{SF}, \mathrm{Hb}, \mathrm{TRF}$ in female primary lung cancer patients}

The characteristics among $\mathrm{SF}, \mathrm{Hb}, \mathrm{TRF}$ and menopausal status, pathological types, stage, TNM stage in female primary lung cancer patients are shown in Table 3. After chi-square test, there was no difference in the constituent ratio of postmenopausal patients and premenopausal patients $(p>0.05)$ (Supplementary Table 1). Menopausal bias had been excluded in groups of pathological types, stage and TNM stage.

Menopausal status, pathological type, stage, TNM stage has no significant effect on anemia. Hb levels did not make any difference in different groups $(p>0.05)$. SF and TRF levels were not statistically different in the pathological types, stage and TNM stage in female lung cancer patients $(p>0.05)$. SF levels in postmenopausal patients were significantly higher than those in premenopausal patients $(p<0.01)$, while TRF levels were just the opposite $(p<0.01)$.

\section{Spearman correlations between $\mathrm{Hb}, \mathrm{SF}$ and TRF in different groups}

Spearman correlation coefficients between $\mathrm{Hb}$, SF and TRF in male patients, postmenopausal patients, premenopausal patients are shown in Table 4. In male patients, TRF levels were positively correlated with $\mathrm{Hb}$ $(p<0.01)$, and negatively correlated with SF $(p<0.01)$. In postmenopausal patients, TRF levels were positively correlated with $\mathrm{Hb}(p<0.01)$. TRF levels were negatively correlated with SF in premenopausal patients $(p<0.01)$. $\mathrm{SF}$ levels were not correlated with $\mathrm{Hb}$ in all three groups $(p>0.05)$.

\section{DISCUSSION}

In both animals and humans, primary neoplasms develop at body sites of excessive iron deposits [15]. There are no significant differences in expression of SF between different pathologic types (squamous cell carcinoma or adenocarcinoma) of lung cancer [6]. Consistent with our findings both in men $(p>0.05)$ and women $(p>0.05)$, SF levels were not statistically different in different pathological types. Strong SF expression was observed in $62 \%$ tumor samples, while it is relatively rare in tumor stroma or normal lung tissue samples $(12 \%$, 9\%) [6]. which revealed that SF levels were significantly 
Table 2: $\mathrm{X} \pm \mathrm{s}$, above/below the normal rang of $\mathrm{SF}, \mathrm{Hb}, \mathrm{TRF}$ in male primary lung cancer patients

\begin{tabular}{|c|c|c|c|c|c|c|c|c|c|}
\hline \multirow{2}{*}{ Parameters } & \multicolumn{3}{|c|}{ Serum ferritin } & \multicolumn{3}{|c|}{ Hemoglobin } & \multicolumn{3}{|c|}{ Transferrin } \\
\hline & $\mathbf{x} \pm \mathbf{s}(\mathbf{u g} / \mathbf{l})$ & above (n) & above( $\%)$ & $\mathbf{x} \pm \mathbf{s}(\mathrm{g} / \mathrm{l})$ & below (n) & below(\%) & $\mathbf{x} \pm \mathbf{s}(\mathrm{g} / \mathrm{l})$ & below (n) & below(\%) \\
\hline Smoking status & $P=0.037$ & & & $P=0.003$ & & & $P=0.718$ & & \\
\hline Smoker & $378.7 \pm 159.1$ & 354 & 85.5 & $130.9 \pm 18.2$ & 108 & 26.1 & $2.2 \pm 0.6$ & 226 & 54.6 \\
\hline Never & $347.7 \pm 153.6$ & 122 & 78.7 & $135.5 \pm 15.1$ & 20 & 12.9 & $2.2 \pm 0.6$ & 83 & 53.5 \\
\hline Pathologic type ${ }^{*}$ & $P=0.486$ & & & $P=0.005$ & & & $P=0.417$ & & \\
\hline Adenocarcinoma & $365.8 \pm 165.3$ & 247 & 82.1 & $134.7 \pm 17.0$ & 57 & 18.9 & $2.3 \pm 0.6$ & 156 & 51.8 \\
\hline $\begin{array}{l}\text { Squamous cell } \\
\text { carcinoma }\end{array}$ & $374.9 \pm 148.0$ & 147 & 86.0 & $128.9 \pm 18.6$ & 48 & 28.1 & $2.2 \pm 0.5$ & 94 & 55.0 \\
\hline $\begin{array}{l}\text { Adeno-squamous } \\
\text { carcinoma }\end{array}$ & $319.9 \pm 157.4$ & 13 & 72.2 & $125.4 \pm 19.0$ & 7 & 38.9 & $2.2 \pm 0.4$ & 11 & 61.1 \\
\hline Small cell carcinoma & $394.0 \pm 148.4$ & 48 & 90.6 & $131.4 \pm 15.7$ & 10 & 18.9 & $2.3 \pm 0.6$ & 29 & 54.7 \\
\hline Not classifiable/Others & $376.8 \pm 157.8$ & 21 & 80.8 & $130.8 \pm 14.1$ & 6 & 23.1 & $2.1 \pm 0.5$ & 19 & 73.1 \\
\hline Stage* & $P=0.055$ & & & $P=0.000$ & & & $P=0.154$ & & \\
\hline $\mathrm{I}$ & $334.3 \pm 167.1$ & 72 & 75.0 & $137.7 \pm 13.8$ & 9 & 9.4 & $2.3 \pm 0.5$ & 41 & 42.7 \\
\hline II & $393.3 \pm 164.6$ & 39 & 84.8 & $136.3 \pm 13.8$ & 8 & 17.4 & $2.3 \pm 0.7$ & 24 & 52.2 \\
\hline III & $366.2 \pm 158.6$ & 162 & 83.5 & $128.3 \pm 19.2$ & 61 & 31.4 & $2.2 \pm 0.5$ & 110 & 56.7 \\
\hline IV & $390.5 \pm 148.2$ & 161 & 88.5 & $132.2 \pm 18.1$ & 41 & 22.5 & $2.2 \pm 0.6$ & 106 & 58.2 \\
\hline Not classifiable & $359.9 \pm 159.1$ & 42 & 82.4 & $132.7 \pm 14.8$ & 9 & 17.6 & $2.2 \pm 0.5$ & 28 & 54.9 \\
\hline $\mathrm{T}^{*}$ & $P=0.000$ & & & $P=0.004$ & & & $P=0.005$ & & \\
\hline $\mathrm{T} 1$ & $313.5 \pm 167.7$ & 54 & 71.1 & $138.1 \pm 13.5$ & 8 & 10.5 & $2.4 \pm 0.6$ & 36 & 47.4 \\
\hline $\mathrm{T} 2$ & $358.6 \pm 163.7$ & 181 & 81.2 & $132.3 \pm 17.0$ & 50 & 22.4 & $2.3 \pm 0.6$ & 114 & 51.1 \\
\hline $\mathrm{T} 3$ & $421.7 \pm 135.3$ & 115 & 93.5 & $128.2 \pm 19.7$ & 41 & 33.3 & $2.1 \pm 0.5$ & 80 & 65.0 \\
\hline $\mathrm{T} 4$ & $383.7 \pm 143.5$ & 77 & 88.5 & $131.9 \pm 19.3$ & 18 & 20.7 & $2.3 \pm 0.6$ & 44 & 50.6 \\
\hline Tx (Not classifiable) & $360.2 \pm 160.1$ & 49 & 81.7 & $132.5 \pm 14.5$ & 11 & 18.3 & $2.2 \pm 0.5$ & 35 & 58.3 \\
\hline $\mathrm{N}^{*}$ & $P=0.133$ & & & $P=0.004$ & & & $P=0.049$ & & \\
\hline N0 & $351.2 \pm 164.7$ & 105 & 80.2 & $136.5 \pm 14.7$ & 15 & 11.5 & $2.3 \pm 0.5$ & 64 & 48.9 \\
\hline N1 & $378.0 \pm 154.0$ & 47 & 87.0 & $134.7 \pm 16.1$ & 11 & 20.4 & $2.3 \pm 0.7$ & 28 & 51.9 \\
\hline $\mathrm{N} 2$ & $365.1 \pm 151.5$ & 170 & 83.7 & $130.3 \pm 18.5$ & 50 & 24.6 & $2.3 \pm 0.5$ & 104 & 51.2 \\
\hline N3 & $401.0 \pm 160.5$ & 105 & 86.8 & $129.1 \pm 19.6$ & 41 & 33.9 & $2.1 \pm 0.5$ & 78 & 64.5 \\
\hline Nx (Not classifiable) & $360.2 \pm 160.1$ & 49 & 81.7 & $132.5 \pm 14.5$ & 11 & 18.3 & $2.2 \pm 0.5$ & 35 & 58.3 \\
\hline$M^{*}$ & $P=0.140$ & & & $P=0.967$ & & & $P=0.752$ & & \\
\hline M0 & $361.5 \pm 162.7$ & 274 & 81.3 & $132.1 \pm 17.6$ & 78 & 23.1 & $2.2 \pm 0.5$ & 175 & 51.9 \\
\hline M1 & $389.5 \pm 148.0$ & 160 & 88.4 & $132.2 \pm 18.1$ & 41 & 22.7 & $2.2 \pm 0.6$ & 106 & 58.6 \\
\hline Mx (Not classifiable) & $359.9 \pm 159.1$ & 42 & 82.4 & $132.7 \pm 14.8$ & 9 & 17.6 & $2.2 \pm 0.5$ & 28 & 54.9 \\
\hline
\end{tabular}

${ }^{*} P>0.05 . \chi^{2}$ test in the composition of smoking patients and non-smoking patients.

different in T stage $(p<0.01)$. There exists a clinically relevant relation between SF concentration and the prognosis of survival in lung cancer patients [15-17], even after adjustment for performance status, age, sex, TNM stage, and histological tumor type [16]. SF may be of no benefit in distinguishing the pathological types, stage, $\mathrm{N}$ stage, M stage of primary lung cancer $(p>0.05)$. There is further evidence that iron content of SF showed positive correlation with iron metabolic parameters and survival [6]. The routine uses of SF, free iron, iron content of SF should be considered in the evaluation and follow-up, which will better assess the status of cancer patients.

In male primary lung cancer patients, anemia prevalence is the highest in stage III, T3, N3. In addition, 
Table 3: $\mathrm{X} \pm \mathrm{s}$, above/below the normal rang of $\mathrm{SF}, \mathrm{Hb}, \mathrm{TRF}$ in female primary lung cancer patients

\begin{tabular}{|c|c|c|c|c|c|c|c|c|c|}
\hline \multirow{2}{*}{ Parameters } & \multicolumn{3}{|c|}{ Serum ferritin } & \multicolumn{3}{|c|}{ Hemoglobin } & \multicolumn{3}{|c|}{ Transferrin } \\
\hline & $x \pm s(u g / l)$ & above (n) & above $(\%)$ & $\mathbf{x} \pm \mathbf{s}(\mathrm{g} / \mathrm{l})$ & below (n) & below $(\%)$ & $\mathbf{x} \pm \mathbf{S}(\mathrm{g} / \mathbf{l})$ & below (n) & below (\%) \\
\hline Menopause & $P=0.000$ & & & $P=0.112$ & & & $P=0.008$ & & \\
\hline Yes & $259.7 \pm 132.1$ & 144 & 80.0 & $123.9 \pm 14.6$ & 24 & 13.3 & $2.3 \pm 0.5$ & 72 & 40.0 \\
\hline No & $121.8 \pm 123.3$ & 19 & 26.4 & $120.7 \pm 14.1$ & 12 & 16.7 & $2.6 \pm 0.7$ & 22 & 30.6 \\
\hline Pathologic type* & $P=0.645$ & & & $P=0.424$ & & & $P=0.149$ & & \\
\hline Adenocarcinoma & $224.7 \pm 143.9$ & 132 & 67.0 & $123.5 \pm 14.8$ & 27 & 13.7 & $2.5 \pm 0.6$ & 69 & 35.0 \\
\hline Squamous cell carcinoma & $197.9 \pm 146.6$ & 15 & 60.0 & $121.8 \pm 13.0$ & 4 & 16.0 & $2.2 \pm 0.6$ & 11 & 44.0 \\
\hline Adeno-squamous carcinoma & $184.0 \pm 155.8$ & 3 & 37.5 & $122.0 \pm 9.4$ & 1 & 12.5 & $2.2 \pm 0.7$ & 5 & 62.5 \\
\hline Small cell carcinoma & $174.6 \pm 113.9$ & 3 & 37.5 & $113.5 \pm 16.3$ & 3 & 37.5 & $2.3 \pm 0.4$ & 3 & 37.5 \\
\hline Not classifiable/others & $244.6 \pm 149.8$ & 10 & 71.4 & $123.5 \pm 14.5$ & 1 & 7.1 & $2.2 \pm 0.5$ & 6 & 42.9 \\
\hline Stage $^{*}$ & $P=0.546$ & & & $P=0.344$ & & & $P=0.348$ & & \\
\hline I & $198.7 \pm 136.4$ & 39 & 60.9 & $125.1 \pm 12.8$ & 8 & 12.5 & $2.5 \pm 0.6$ & 19 & 29.7 \\
\hline II & $216.5 \pm 120.2$ & 12 & 70.6 & $118.2 \pm 17.5$ & 4 & 23.5 & $2.3 \pm 0.4$ & 6 & 35.3 \\
\hline III & $244.0 \pm 156.3$ & 43 & 71.7 & $124.0 \pm 13.0$ & 8 & 13.3 & $2.3 \pm 0.5$ & 24 & 40.0 \\
\hline IV & $220.2 \pm 139.5$ & 60 & 61.9 & $122.3 \pm 14.9$ & 12 & 12.4 & $2.4 \pm 0.6$ & 37 & 38.1 \\
\hline Not classifiable & $222.1 \pm 176.5$ & 9 & 64.3 & $119.4 \pm 20.1$ & 4 & 28.6 & $2.3 \pm 0.6$ & 8 & 57.1 \\
\hline $\mathrm{T}^{*}$ & $P=0.153$ & & & $P=0.086$ & & & $P=0.058$ & & \\
\hline $\mathrm{T} 1$ & $192.3 \pm 119.5$ & 42 & 67.7 & $126.6 \pm 13.0$ & 8 & 12.9 & $2.6 \pm 0.5$ & 14 & 22.6 \\
\hline $\mathrm{T} 2$ & $225.9 \pm 148.5$ & 65 & 61.3 & $123.0 \pm 12.8$ & 11 & 10.4 & $2.4 \pm 0.6$ & 37 & 34.9 \\
\hline $\mathrm{T} 3$ & $266.4 \pm 158.6$ & 28 & 75.7 & $118.9 \pm 17.4$ & 8 & 21.6 & $2.3 \pm 0.6$ & 18 & 48.6 \\
\hline $\mathrm{T} 4$ & $205.4 \pm 135.9$ & 14 & 56.0 & $119.7 \pm 16.3$ & 5 & 20.0 & $2.3 \pm 0.7$ & 14 & 56.0 \\
\hline Tx (Not classifiable) & $211.2 \pm 155.5$ & 14 & 63.6 & $123.4 \pm 17.6$ & 4 & 18.2 & $2.4 \pm 0.7$ & 11 & 50.0 \\
\hline $\mathrm{N}^{*}$ & $P=0.101$ & & & $P=0.787$ & & & $P=0.038$ & & \\
\hline No & $197.0 \pm 135.7$ & 45 & 59.2 & $124.2 \pm 14.2$ & 10 & 13.2 & $2.5 \pm 0.6$ & 22 & 28.9 \\
\hline N1 & $186.9 \pm 111.3$ & 12 & 57.1 & $123.6 \pm 9.8$ & 1 & 4.8 & $2.6 \pm 0.7$ & 6 & 28.6 \\
\hline N2 & $228.1 \pm 140.3$ & 60 & 68.2 & $122.8 \pm 15.6$ & 14 & 15.9 & $2.3 \pm 0.5$ & 35 & 39.8 \\
\hline N3 & $264.3 \pm 163.2$ & 32 & 71.1 & $120.7 \pm 13.3$ & 7 & 15.6 & $2.2 \pm 0.6$ & 20 & 44.4 \\
\hline Nx (Not classifiable) & $211.2 \pm 155.5$ & 14 & 63.6 & $123.4 \pm 17.6$ & 4 & 18.2 & $2.4 \pm 0.7$ & 11 & 50.0 \\
\hline $\mathrm{M}^{*}$ & $P=0.999$ & & & $P=0.488$ & & & $P=0.661$ & & \\
\hline M0 & $220.1 \pm 144.1$ & 94 & 66.7 & $123.8 \pm 13.6$ & 20 & 14.2 & $2.4 \pm 0.6$ & 49 & 34.8 \\
\hline M1 & $220.2 \pm 139.5$ & 60 & 61.9 & $122.3 \pm 14.9$ & 12 & 12.4 & $2.4 \pm 0.6$ & 37 & 38.1 \\
\hline Mx (Not classifiable) & $222.1 \pm 176.5$ & 9 & 64.3 & $119.4 \pm 20.1$ & 4 & 28.6 & $2.3 \pm 0.6$ & 8 & 57.1 \\
\hline
\end{tabular}

${ }^{*} P>0.05 . \chi^{2}$ test in the composition of postmenopausal patients and premenopausal patients.

T3 has the highest SF average levels, the highest proportion of SF above the normal range, the lowest TRF average and the highest proportion of TRF below the normal range. Squamous cell carcinoma and adenosquamous cell carcinoma have higher rates of anemia. The phenomenon was not found in women. We note that the anemia rate in women with small cell lung cancer is obviously higher than that of other pathological types $(37.5 \%)$. But because of the small number of samples of squamous cell carcinoma, adeno-squamous cell carcinoma and small cell carcinoma, the correlation between pathological type and anemia in female primary lung cancer patients cannot be determined for the time being. In some studies, the anemia rate in lung cancer patients is $57.6 \%$ [6], 57.9\% [18], higher than our study. Their subjects were in or after anti-tumor therapy. Chemotherapy causes myelosuppression [19] and surgery leads to blood loss, which increases anemia rates. Pretreatment of anemia can improve the overall survival rate of lung cancer and control disease progression [20]. 
Table 4: Spearman correlation between $\mathrm{Hb}, \mathrm{SF}$ and TRF values in different groups

\begin{tabular}{|c|c|c|c|c|}
\hline Parameters & & SF & $\mathbf{H b}$ & TRF \\
\hline \multirow[t]{3}{*}{ Men } & SF & 1.000 & & \\
\hline & $\mathrm{Hb}$ & -0.067 & 1.000 & \\
\hline & TRF & $-0.257^{* *}$ & $0.366^{* *}$ & 1.000 \\
\hline \multirow[t]{3}{*}{ Postmenopause } & $\mathrm{SF}$ & 1.000 & & \\
\hline & $\mathrm{Hb}$ & 0.042 & 1.000 & \\
\hline & $\mathrm{TRF}$ & -0.130 & $0.270^{* *}$ & 1.000 \\
\hline \multirow[t]{3}{*}{ Premenopause } & $\mathrm{SF}$ & 1.000 & & \\
\hline & $\mathrm{Hb}$ & 0.042 & 1.000 & \\
\hline & TRF & $-0.390^{* *}$ & 0.174 & 1.000 \\
\hline
\end{tabular}

The large scale of epidemic results showed the significantly negative relations between SF levels and total testosterone, free testosterone, estradiol and sex hormone-binding protein in men, there was borderline negative relation between SF levels and estradiol in men [21]. However, there is no such big data for women. Menopause may be the common link that resulted in higher SF in women $[22,23]$. Postmenopausal women who take estrogen have lower levels of SF than those who do not take estrogen [24]. High estrogen levels increase TRF levels [25]. Premenopausal women have higher carbohydrate-deficient TRF levels than postmenopausal women [26, 27], which was similar to our findings. TRF levels in premenopausal patients were significantly higher than those in postmenopausal patients $(p<0.01)$. SF levels in men were higher than those in women, and the levels of SF in postmenopausal women were higher than those in premenopausal women, so blood loss monthly was also an important factor in maintaining low and normal $\mathrm{SF}$ levels. Blood loss monthly did not decrease $\mathrm{Hb}$ levels $(p>0.05)$. TRF levels were negatively correlated with SF in premenopausal patients $(p<0.01)$, TRF levels were positively correlated with $\mathrm{Hb}$ in postmenopausal patients $(p<0.01)$. While in male patients, TRF levels were both positively correlated with $\mathrm{Hb}(p<0.01)$ and negatively correlated with SF $(p<0.01)$. We were not clear of the reason. We speculated that SF, TRF, Hb levels were regulated by different mechanisms and were of different physiological significance in men, postmenopausal women, premenopausal women. Considering tumor patients, it may be more complicated.

Our results showed SF levels in smokers with primary lung cancer were not significantly higher than non-smokers with primary lung cancer $(p=0.037)$. There is recent evidence that the non-smoking and smoking healthy men exhibited no difference in SF levels [28]. Higher
SF levels are associated with a higher Body Mass Index $[21,28]$. However, another study shows that smoking has an effect on SF. The reductants present in cigarette smoke can readily mobilize iron from SF, leading to lipid peroxidation and cell damage [29]. More research and data are needed to discover the relation between smoking and SF. But smoking had an obvious effect on anemia. Smokers had a lower $\mathrm{Hb}$ level than non-smokers, and anemia was twice as high as non-smokers.

SF has emerged as an excellent and promising protein-based nanocage thanks to its unique architecture, surface properties and high biocompatibility. SF nanocages may ensure a proper drug delivery and release [30-32], such as cisplatin, carboplatin, gefitinib, doxorubicin [33-36]. Based on the results of this study, the next step was to investigate the efficacy of SF encapsulated chemotherapeutic agents in the treatment of primary lung cancer, with a focus on the effectiveness of the treatment and the diversity in the different populations.

SF has the ability to store iron [5], participate in inflammation and infection [7-10], participate in cancer and other functions $[1,2,15]$. SF may represent different functions at different stages of different populations. This may be related to the iron content of SF. Although many of the functions of SF have been discovered and exploited, more advanced and sophisticated detection methods are needed to distinguish between different functions of SF, more prospective work is needed to confirm SF's more functions in disease.

\section{MATERIALS AND METHODS}

\section{Patients}

This study was approved by the ethics committee of the Guangxi Medical University Affiliated Tumor 
Hospital with an Ethics approval number of KS2016(36). When the patient suspected he had lung cancer, they were first admitted to the thoracic tumor surgery department. We systematically reviewed all patients who had been hospitalized in the thoracic oncology department from October 2014 to April 2017. Cases with other malignancies and/or no pathology and/or no imaging were excluded. The clinical and pathological diagnosis of primary lung cancer was based on the seventh edition of the TNM classification for lung cancer [9-11]. All cases had not been treated with anti-tumor therapy, such as surgery, chemotherapy, radiotherapy, biological therapy, endocrine therapy, Chinese medicine treatment, hyperthermia and radiofrequency ablation therapy. Complete and detailed data were available for all cases.

\section{Imaging examination}

Patients were scanned by $5.0 \mathrm{~mm}$ slice thickness from the thoracic cavity to the septum using Siemens 64 row CT machine. All scans were read and diagnosed by two or more senior imaging doctors independently.

\section{Pathological examination}

All primary lung cancer patients underwent surgical biopsy, biopsy under ultrasound or conventional bronchoscopy biopsy. Diagnostic results were given by at least two senior pathologists independently.

\section{Laboratory assays}

Each patient agreed to undergo fasting blood the next morning after admission, which is a routine medical practice. The results of the blood test were obtained on that day. SF and TRF were assayed using Siemens ADVIA 2400. Hb was assayed using Mindray BC-6900. All assays were performed according to instrument and reagent specifications, with strict whole process quality control monitoring of the results. The results were accurate. The normal ranges of men's SF, $\mathrm{Hb}$, and TRF were $15 \mathrm{ug} / \mathrm{l}$ $200 \mathrm{ug} / 1,120 \mathrm{~g} / \mathrm{l}-160 \mathrm{~g} / 1,2.2 \mathrm{~g} / \mathrm{l}-4 \mathrm{~g} / 1$; The normal ranges of women's SF, $\mathrm{Hb}$, and TRF were $12 \mathrm{ug} / \mathrm{l}-150 \mathrm{ug} / \mathrm{l}, 110 \mathrm{~g} / \mathrm{l}$ $150 \mathrm{~g} / 1,2.2 \mathrm{~g} / \mathrm{l}-4 \mathrm{~g} / \mathrm{l}$.

\section{Statistical analyses}

IBM SPSS21.0 software was applied for statistical analysis. The levels adopted for significance were $p>0.05$ and $p<0.01$ (two-tailed). Numerical variables were represented as mean \pm standard deviation $(x \pm s)$. Variance analysis was used to compare the deference for multiple groups and non-paired $t$-test was used to analyze the two groups after homogeneity of variance test. $\chi^{2}$-test was used to compare the constituent ratio of two groups. Correlations between parameters were done by Spearman correlation.

\section{Author contributions}

Conception and design: Bo Zhu; Zhongqing Chen Chao Ou.

Collection of clinical data: Zhongqing Chen; Yuxuan Li.

Analysis and interpretation of data: Zhongqing Chen; Chao Ou; Yuxuan Li.

Writing, review, and/or revision of the manuscript: Zhongqing Chen; Chao Ou.

Administrative, technical, or material support: Bo Zhu.

\section{ACKNOWLEDGMENTS}

We thank the anonymous clinicians for several insightful comments that significantly improved the paper.

\section{CONFLICTS OF INTEREST}

The authors declare no conflicts of interest.

\section{FUNDING}

This work was supported by the National High Technology Research and Development Program of China (863 Program) (grant number 2014AA022304).

\section{REFERENCES}

1. Torti SV, Torti FM. Iron and cancer: more ore to be mined. Nat Rev Cancer. 2013; 13:342-355.

2. Manz DH, Blanchette NL, Paul BT, Torti FM, Torti SV. Iron and cancer: recent insights. Ann N Y Acad Sci. 2016; 1368:149-161.

3. Basuli D, Tesfay L, Deng Z, Paul B, Yamamoto Y, Ning G, Xian W, McKeon F, Lynch M, Crum CP, Hegde P, Brewer $\mathrm{M}$, Wang $\mathrm{X}$, et al. Iron addiction: a novel therapeutic target in ovarian cancer. Oncogene. 2017; 36:4089-4099.

4. Fonseca-Nunes A, Jakszyn P, Agudo A. Iron and cancer risk--a systematic review and meta-analysis of the epidemiological evidence. Cancer Epidemiol Biomarkers Prev. 2014; 23:12-31.

5. World Health Organization, Centers for Disease Control and Prevention. Assessing the iron status of populations. Geneva, Switzerland; WHO Press; 2004.

6. Kukulj S, Jaganjac M, Boranic M, Krizanac S, Santic Z, Poljak-Blazi M. Altered iron metabolism, inflammation, transferrin receptors, and ferritin expression in non-smallcell lung cancer. Med Oncol. 2010; 27:268-277.

7. Righetti AA, Wegmuller R, Glinz D, Ouattara M, Adiossan LG, N'Goran EK, Utzinger J, Hurrell RF. Effects of inflammation and Plasmodium falciparum infection on soluble transferrin receptor and plasma ferritin concentration in different age groups: a prospective 
longitudinal study in Cote d'Ivoire. Am J Clin Nutr. 2013; 97:1364-1374.

8. Thurnham DI, McCabe LD, Haldar S, Wieringa FT, Northrop-Clewes CA, McCabe GP. Adjusting plasma ferritin concentrations to remove the effects of subclinical inflammation in the assessment of iron deficiency: a metaanalysis. Am J Clin Nutr. 2010; 92:546-555.

9. Nairz M, Haschka D, Demetz E, Weiss G. Iron at the interface of immunity and infection. Front Pharmacol. 2014; 5:152.

10. Kim SE, Kim UJ, Jang MO, Kang SJ, Jang HC, Jung SI, Lee SS, Park KH. Diagnostic use of serum ferritin levels to differentiate infectious and noninfectious diseases in patients with fever of unknown origin. Dis Markers. 2013; 34:211-218.

11. Efstathiou SP, Pefanis AV, Tsiakou AG, Skeva II, Tsioulos DI, Achimastos AD, Mountokalakis TD. Fever of unknown origin: discrimination between infectious and non-infectious causes. Eur J Intern Med. 2010; 21:137-143.

12. Ludwig H, Muldur E, Endler G, Hubl W. Prevalence of iron deficiency across different tumors and its association with poor performance status, disease status and anemia. Ann Oncol. 2013; 24:1886-1892.

13. Spada PL, Rossi C, Alimonti A, Bocca B, Cozza V, Ricerca BM, Bocci MG, Vulpio C, De Sole P. Ferritin iron content in haemodialysis patients: comparison with septic and hemochromatosis patients. Clin Biochem. 2008; 41:997-1001.

14. Zhang L, Lv J, Liao C. Dietary exposure estimates of 14 trace elements in Xuanwei and Fuyuan, two high lung cancer incidence areas in China. Biol Trace Elem Res. 2012; 146:287-292.

15. Weinberg ED. The role of iron in cancer. Eur J Cancer Prev. 1996; 5:19-36.

16. Milman N, Pedersen LM. The serum ferritin concentration is a significant prognostic indicator of survival in primary lung cancer. Oncol Rep. 2002; 9:193-198.

17. Fracchia A, Ubbiali A, El Bitar O, Pacetti M, Sommariva E, Arreghini M, Longhini E, Bonalumi GP. A comparative study on ferritin concentration in serum and bilateral bronchoalveolar lavage fluid of patients with peripheral lung cancer versus control subjects. Oncology. 1999; 56:181-188

18. He S, Lingyun Z, Yunpeng L. [Analysis of postoperative chemotherapy-related anemia in elderly cancer patients]. [Article in Chinese]. Zhonghua Zhong Liu Za Zhi. 2015; 37:290-292

19. Genova C, Rijavec E, Grossi F. Hematopoietic growth factors in lung cancer. Curr Opin Oncol. 2016; 28:135-144.

20. Shaverdian N, Veruttipong D, Wang J, Kupelian P, Steinberg M, Lee P. Pretreatment Anemia Portends Poor Survival and Nonlocal Disease Progression in Patients with Stage I NonSmall Cell Lung Cancer Treated with Stereotactic Body Radiation Therapy. J Thorac Oncol. 2016; 11:1319-1325.
21. Liu Z, Ye F, Zhang H, Gao Y, Tan A, Zhang S, Xiao Q, Zhang B, Huang L, Ye B, Qin X, Wu C, Lu Z, et al. The association between the levels of serum ferritin and sex hormones in a large scale of Chinese male population. PLoS One. 2013; 8:e75908.

22. Lee BK, Kim Y. Menopause may be the common link that resulted in the association between higher serum ferritin level and lower bone mineral density in women \&gt; $/=45$ years of age. Osteoporos Int. 2014; 25:787.

23. Cho GJ, Shin JH, Yi KW, Park HT, Kim T, Hur JY, Kim SH. Serum ferritin levels are associated with metabolic syndrome in postmenopausal women but not in premenopausal women. Menopause. 2011; 18:1120-1124.

24. Penckofer S, Schwertz D. Improved iron status parameters may be a benefit of hormone replacement therapy. J Womens Health Gend Based Med. 2000; 9:141-151.

25. Shifren JL, Rifai N, Desindes S, McIlwain M, Doros G, Mazer NA. A comparison of the short-term effects of oral conjugated equine estrogens versus transdermal estradiol on C-reactive protein, other serum markers of inflammation, and other hepatic proteins in naturally menopausal women. J Clin Endocrinol Metab. 2008; 93:1702-1710.

26. Stauber RE, Vollmann H, Pesserl I, Jauk B, Lipp R, Halwachs G, Wilders-Truschnig M. Carbohydrate-deficient transferrin in healthy women: relation to estrogens and iron status. Alcohol Clin Exp Res. 1996; 20:1114-1117.

27. Leusink GL, Smeets-Goevaers CG, Breed SA, Keyzer JJ, van Pelt J. Carbohydrate-deficient transferrin in relation to the menopausal status of women. Alcohol Clin Exp Res. 2000; 24:172-175.

28. Li S, Lin L, Mo Z, Qin X, Lv H, Gao Y, Tan A, Yang X, Huang $S$, Chen Z. Reference values for serum ferritin in Chinese Han ethnic males: results from a Chinese male population survey. Clin Biochem. 2011; 44:1325-1328.

29. Lapenna D, de Gioia S, Mezzetti A, Ciofani G, Consoli A, Marzio L, Cuccurullo F. Cigarette smoke, ferritin, and lipid peroxidation. Am J Respir Crit Care Med. 1995; 151:431-435.

30. Truffi M, Fiandra L, Sorrentino L, Monieri M, Corsi F, Mazzucchelli S. Ferritin nanocages: A biological platform for drug delivery, imaging and theranostics in cancer. Pharmacol Res. 2016; 107:57-65.

31. de Turris V, Cardoso Trabuco M, Peruzzi G, Boffi A, Testi C, Vallone B, Celeste Montemiglio L, Georges AD. Humanized archaeal ferritin as a tool for cell targeted delivery. Nanoscale. 2017; 9:647-655.

32. Bhushan B, Kumar SU, Matai I, Sachdev A, Dubey P, Gopinath P. Ferritin nanocages: a novel platform for biomedical applications. J Biomed Nanotechnol. 2014; 10:2950-2976.

33. Pontillo N, Ferraro G, Helliwell JR, Amoresano A, Merlino A. X-ray Structure of the Carboplatin-Loaded Apo-Ferritin Nanocage. ACS Med Chem Lett. 2017; 8:433-437. 
34. Kuruppu AI, Zhang L, Collins H, Turyanska L, Thomas NR, Bradshaw TD. An Apoferritin-based Drug Delivery System for the Tyrosine Kinase Inhibitor Gefitinib. Nanoscale. 2015; 4:2816-2821.

35. Yang Z, Wang X, Diao H, Zhang J, Li H, Sun H, Guo Z. Encapsulation of platinum anticancer drugs by apoferritin. Chem Commun (Camb). 2007:3453-3455.
36. Bellini M, Mazzucchelli S, Galbiati E, Sommaruga S, Fiandra L, Truffi M, Rizzuto MA, Colombo M, Tortora P, Corsi F, Prosperi D. Protein nanocages for self-triggered nuclear delivery of DNA-targeted chemotherapeutics in Cancer Cells. J Control Release. 2014; 196:184-196. 